\title{
Louise Bourgeois: metafísica e arte da intimidade
}

\section{Artículo de reflexión}

\section{Paulo Alexandre e Castro}

Inst. de Estudos Filosóficos-Universidade de Coimbra, Portugal

paecastro@gmail.com

Recibido: 13 de julio de 2021

Aceptado: 16 de septiembre de 2021

Como citar este artículo: Castro, P. A. (2022). Louise

Bourgeois: metafísica e arte da intimidade. Calle14: revista de investigación en el campo del arte. 17(31), pp. 178-193. DOI: https://doi.org/10.14483/21450706.18704

\section{(2) (1)}

https://creativecommons.org/licenses/by/4.0/deed.es 


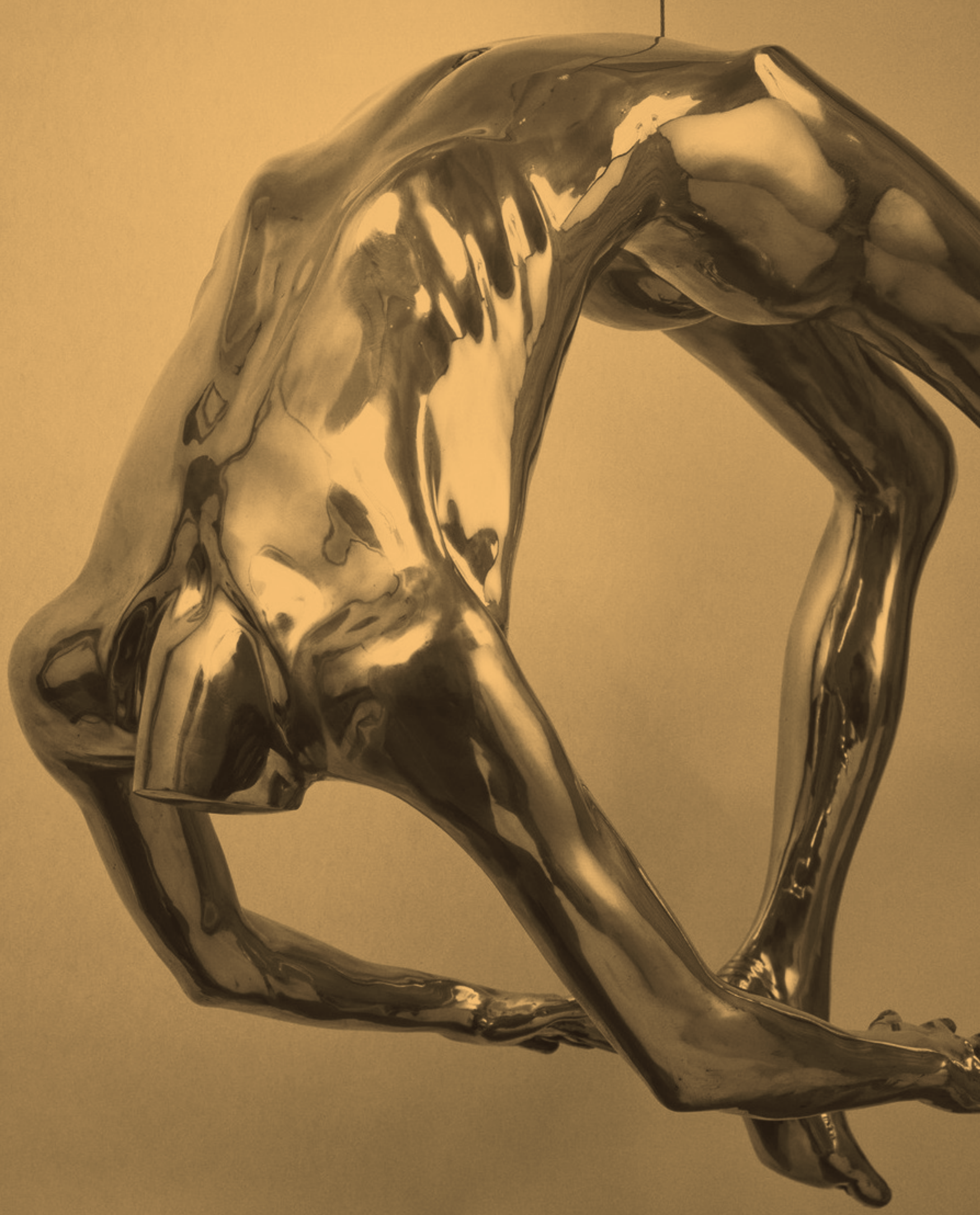




\title{
Resumen
}

Este ensayo se centra, por un lado, en la obra pictórica y, por otro, en las reflexiones filosóficas que produjo Louise Bourgeois y que fueron recogidas en el libro Destruction of the Father. Reconstruction of the Father - Writings and Interviews 1923-1997. Qué conceptos utiliza la artista, cómo los interpreta y expresa, cómo los encaja en una filosofía del arte o la estética (por ejemplo, su controvertida posición frente a Duchamp o su admiración por Francis Bacon), y qué lugar reserva para las emociones, ya sea desde el punto de vista de la creación artística como desde el punto de vista de su vida personal. Tras este análisis, se presentan el concepto de intimidad y la perspectiva de un arte y una metafísica de la intimidad.

\section{Palabras clave}

Abstracción; emociones; erotismo; intimidad; Louise Bourgeois.

\section{Louise Bourgeois: metaphysics and the art of intimacy}

\begin{abstract}
This essay focuses, on the one hand, on the pictorial work and, on the other, on the philosophical reflections of Louise Bourgeois, collected in the book Destruction of the Father / Reconstruction of the Father - Writings and Interviews 1923-1997. What concepts does the artist use, how does she interpret and express them, how does she fit them into a philosophy of art or aesthetics (for example, her controversial position towards Duchamp or her admiration for Francis Bacon), and what place does she reserve for emotions, both from the point of view of artistic creation and from the point of view of her personal life. After this analysis, we introduce the concept of intimacy and the perspective of an art and a metaphysics of intimacy.
\end{abstract}

\section{Keywords}

Abstraction; emotions; eroticism; privacy; Louise Bourgeois

Louise Bourgeois : métaphysique et art de l'intimité

\section{Résumé}

Cet essai porte, d'une part, sur l'œuvre picturale et, d'une autre, sur les réflexions philosophiques de Louise Bourgeois rassemblées dans le livre Destruction du Père / Reconstruction du Père Écrits et Entretiens 1923-1997. Quels concepts l'artiste utilise-t-elle, comment les interprète-telle et les exprime-t-elle, comment les inscrit-elle dans une philosophie de l'art ou de l'esthétique (par exemple, sa position controversée envers Duchamp ou son admiration pour Francis Bacon), et quelle place réserve-t-elle pour les émotions, tant du point de vue de la création artistique que du point de vue de sa vie personnelle. Après cette analyse, le concept d'intimité et la perspective d'un art et d'une métaphysique de l'intimité sont présentés.

\section{Mots clés}

Abstraction ; émotions ; érotisme ; intimité ; Louise Bourgeois

\section{Louise Bourgeois: metafísica e arte da intimidade}

\section{Resumo}

Este ensaio se centra, por um lado, na obra pictórica e, por outro, nas reflexões filosóficas que produziu Louise Bourgeois e que foram coletadas do livro Destruction of the Father. Reconstruction of the Father - Writings and interviews 1923-1997. Que conceitos utiliza a artista, como os interpreta e expressa, como os encaixa em uma filosofia da arte ou da estética (por exemplo, sua posição controversa em relação a Duchamp ou sua admiração por Francis Bacon) e 
que lugar reserva para as emoções, tanto a partir do ponto de vista da criação artística como de sua vida pessoal. Após essa análise, se apresentam o conceito de intimidade e a perspectiva de uma arte e de uma metafisica da intimidade.

\section{Palavras Chave}

Abstração, emoções, erotismo, intimidade, Louise Bourgeois

\section{Louise Bourgeois: suti runa iachachiku, ruraikuna nukanchimanda apachingapa}

\section{Maillallachiska}

Kaipi kawariku Sugllapi kawai, pangapi ruraskata iuiarispa kilkaskata Louise Bourgeois suti, paikuna atanchiska panga, kilkaskata sug libromanda taitata tukuchiska taitata kausachispa kilkaska pangapi, kawachispa Tukui kunata kai watapi 1923- 1997. ministiska kai runa kaikuna rurangapa. Imatak iachiska imasa sugkunata. kawachiska imasatak churaska chagpipi kai ruraita allilla kawaringapa kaipi pudinchi ninga tiaska llapa ullarii kai runa Duchamp suti, chasalla tukuikuna ugnarii kawaspa kai runa Francis Bacon sutimanda maipitak sakiska llapa allilla iachiura. Kati samuspa kawa ima rurami tiami sugkunata kawaspa.

\section{Rimangapa Ministidukuna}

Anchurii; Ilapa aliachi; munakui llapa kawachispa; nukanchilla kawanakui; Louise Bourgeoi chasa suti 


\section{Uma filosofia da arte/do artista em Louise Bourgeois}

Em Louise Bourgeois encontramos reflectida uma filosofia prática de notável (e invejável) coerência intelectual. Uma filosofia que se materializa não só na discursividade filosófica mas igualmente na actuação plástica e vivencial (quer ao nível das obras que Louise Bourgeois produz, quer ao nível da sua vida pessoal). A sua formação académica (começada com um bacharelato em filosofia e depois com o estudo de cálculo e geometria na Sorbonne) aliada a uma forte personalidade e às fortes convicções sobre aquilo que deve ser a arte e o artista, geram uma obra impar no panorama das artes plásticas de todo o século XX. Não iremos abordar aqui, como ocorre em tantos lugares, a relação freudiana da artista com o pai, os possíveis traumas e complexos, as leituras da obra a partir da bio-grafia (como por exemplo acontece com Frida Khalo). Interessa considerar a artista enquanto criadora, as obras, a filosofia, a intimidade da arte e do mundo, ou a intimidade da arte com o mundo transmitida pela sua obra, mostrar o acesso da artista ao imaginário.

Louise Bourgeois procura realizar a simplicidade na sua obra, ou melhor, procura realizar a transparência, por oposição à opacidade, por oposição à máscara. Por exemplo, na entrevista com Paulo Herkenhoff esta noção serve a Louise Bourgeois para enunciar dois propósitos, o do seu trabalho (da sua pesquisa) e da falsidade da utilização de máscaras: para Louise Bourgeois "não há máscaras no seu trabalho."(Herkenhoff, 2003, p. 8).

A noção de transparência em Louise Bourgeois adquire os contornos de uma máxima e traduz a ideia de simplicidade, de clareza, de deixar ver e ou de permitir-se ver, e é nesse sentido que vão as palavras da nossa artista quando refere: «a transparência interessa-me. Eu quero ser transparente, se as pessoas pudessem ver através de mim, não conseguiriam evitar apaixonarem-se, [gostarem de mim] perdoarem-me. Qual a diferença entre as duas? Nenhuma». (Bourgeois, 2003, p. 132).

A transparência apresenta a clarividência, apresenta (um)a verdade. Uma máscara oculta, não deixa ver, não revela, produz a falsidade da imagem, inibe a verdade, ou melhor, a máscara é aquele dispositivo que me permite fingir para revelar uma outra coisa. Assim, a máscara é um obstáculo que se coloca defronte da vida e por isso mesmo é geradora de tensões, de enganos.
O que é dado a ver, o que se deixa ver na transparência do mundo, constitui e constitui-se como aparecer, como dado na sua simplicidade diante do sujeito. Este desafio pela transparência do sujeito-objecto é a tarefa maior de qualquer artista plástico, pois exige o esforço da abstracção que o encaminha para o essencial, para síntese da representação. Ora, é precisamente este desafio que não é compreendido por todos e provavelmente não é acessível a todos na leitura da obra da nossa artista (de que foi exemplo William Rubin no seu artigo dos anos 60).

O ser obstinado com a arte, com o processo criativo implica a realização da viagem à interioridade, a essência daquilo que marca as coisas na sua existência. 0 gosto pelo existencialismo que Louise Bourgeois demonstra vai um pouco neste sentido, isto é, o gosto pela experiência pura das coisas na sua simplicidade, na sua existência aí-dada (Bourgeois, 2003, p. 230).

A marca de uma possível metafísica da intimidade deixa-se gravar a partir destas vivências que realizam o jogo da interioridade-exterioridade. Por isso a arte não tem nada que ver com a história da arte. Assim, cabe perguntar, qual a função da arte? E o que é ser artista?

As respostas de Louise Bourgeois surpreendem não tanto pela originalidade mas pela forma como as defende, pela forma como usa os argumentos. A «arte torna as pessoas civilizadas. Mais civilizadas, caso contrário elas comiam-se umas às outras, bater-se-iam entre si», diz Bourgeois na entrevista com Christiane Mennicke, e dado que a arte é uma linguagem universal, ela permite uma aproximação entre os seres (Mennicke, 2003, p. 187).

Este carácter civilizacional da arte é como uma passagem e um percurso para a(s) intimidade(s), uma vez que a procura da exibição dum mundo interior proporciona a sua descoberta ou parte desse mundo interno. Ao contrário de Pirandello que referia que cada pessoa transporta o seu mundo nas palavras o que causaria um problema de comunicação (Pirandello, 1993, p. 40), Louise Bourgeois acredita no poder da arte e no poder de comunicação da arte. A arte, parece-nos, partilha de um mesmo princípio filosófico que preside à inter-subjectividade: a existência da alteridade radica na descoberta de mim no e pelo olhar que obtenho dos outros, tal como a obra de arte ganha a sua consistência e a sua existência pelo olhar que lançamos sobre ela. Diz Bourgeois na entrevista a Mennicke: «a função da 


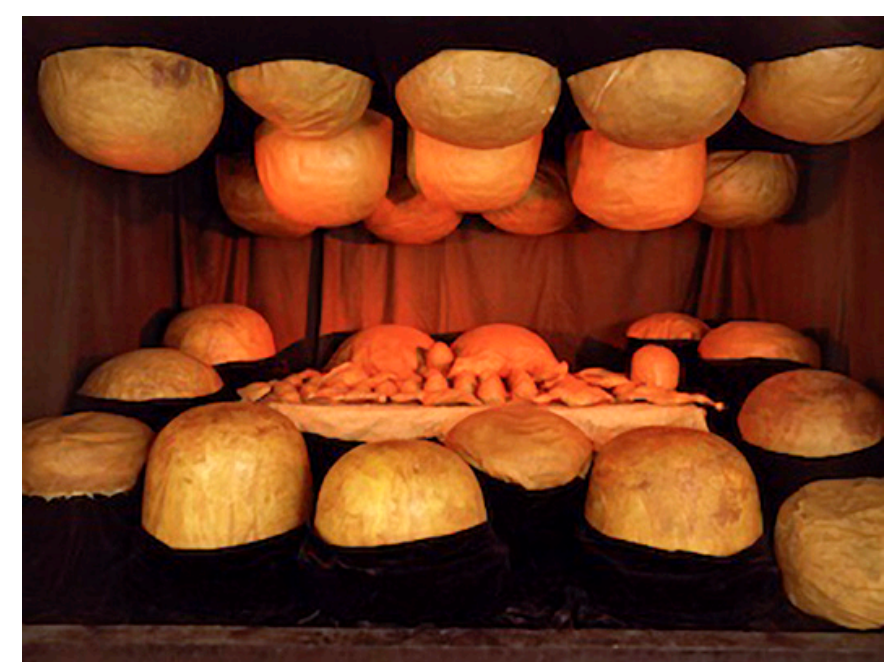

minha arte é provocar as pessoas e antagonizá-las, e obrigá-las a uma reavaliação». (Mennicke, 2003, p. 187).

No fundo Louise Bourgeois ao dar esta resposta está a apelar à compreensão da relação do indivíduo com a vida - arte tem a ver com a vida. Repare-se pois que a arte segundo este ponto de vista, será aquilo que permite a sustentação de uma esfera que é como que uma 'interrupção' na nossa vida, e que permite o aflorar da questão, do pôr em causa. Isto não significa que se esteja ou que Louise Bourgeois esteve a criar a perspectiva da arte como comunicação, a artista diz mesmo que não faz o «jogo da comunicação», quer dizer, que não atribui e defende a função essencial da arte como comunicação (Bourgeois, 2003, p. 162). Obrigar as pessoas a re-avaliar, a suspender a banalidade do quotidiano, fazê-las entrar na intimidade das coisas, fazê-las sentirem-se intimidadas. Embora algo distinta da posição do mestre da arte bruta, Jean Dubuffet apelava igualmente para o carácter subversivo da arte, para a intimidação do grande número de pessoas (contrária à noção de que a arte se faz para elites), apostando não no «voltar as costas ao público, mas em enfrentá-lo». (Dubufett, 1971, p. 37). Um pouco como Sorel pretendia ao procurar "limpar a memória" da cultura e tradição impostas socialmente, para re-inventar o lugar do individuo. ${ }^{1}$

A arte acontece em Louise Bourgeois. O acto artístico não é, não pode ser um acto descritível, pois como refere Filomena Molder, a inspiração escapa à intencionalidade (à intenção de fazer deste ou daquele modo), e o artista apenas revela o que quer fazer quando está

1 Cf. Sorel, George, « Le valeur social de l'art », in Revue de Métaphysique et de Morale, 9-3 (1901) : 251-278.
Imagen 1. Louise Bourgeois, "The Destruction of the Father", 1974. Plaster, latex, wood, fabric and red light, 93 5/8 x 142 5/8 x 97 7/8 in. Courtesy Cheim \& Read, Hauser \& Wirth and Galerie Karsten Greve. Photo: Rafael Lobato. https://tinyurl.com/3a7zuxac

a fazer (Molder, 2005, p. 241). É no processo criativo que acontece a arte, que se dá o aparecer da obra enquanto tal, e Bourgeois sabe que muitas vezes se começa a trabalhar apenas com uma ideia, e que só depois vem a obra. ${ }^{2}$ A "revelação" e a entrega íntima surge nesse dar-se do acto de criar, pelo que a arte é um privilégio quer para o artista (enquanto acto de criação) quer para o público que terá o acesso à arte. ${ }^{3}$ Mais do que a arte ser uma experiência íntima do artista (dado que o artista contemporâneo como que vive uma experiência de abandono, de isolamento, de solidão o que vai de encontro às palavras de Francis Bacon quando refere que não há «comunidade artística»), a arte tem a ver com a vida. Tal como a vida, a arte é essa busca insatisfeita e incessante por algo (é como refere Louise Bourgeois uma tragédia), "a arte vem da vida". (Bourgeois, 2003, p.227). A função da arte é retratar esta condição da vida, é procurar aceder à intimidade que a vida proporciona.

2 «First, you have to conceptualize what you want to do; you have to have an idea. The idea, as I said before, comes from a failure somewhere, a failure of power somewhere. [...] All I can do is to have these flashes of intense experience that are represented by this, and this, and this, and this. This is one of the bases of my repeated work». Bourgeois em entrevista com Stuart Morgan, pp. 158-160.

3 «Art is a privilege, a blessing, a relief. Privilege means that you are a favourite, that what you do is not completely to your credit, not completely due to you, but is a favour conferred upon you». (Bourgeois, 2003, p. 164). No aforismo 49, página 227, percebemos que esta benção para o artista é também a garantia da sua sanidade, e ao sê-lo ele está apto para suportar isso mesmo: «If a person is an artist, it is a guarantee of sanity. He is able to take the torment». 


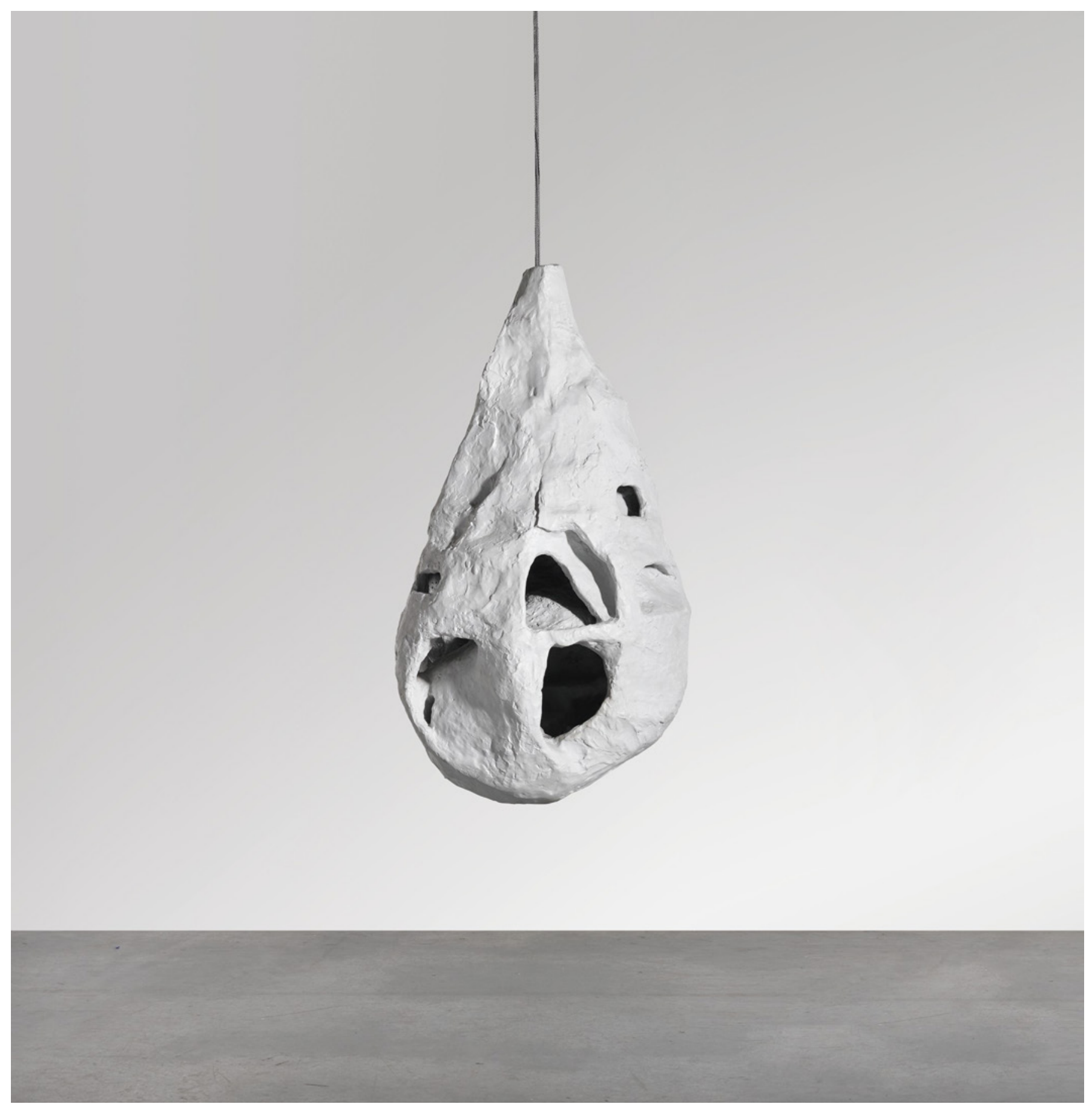

Imagen 2. Louise Bourgeois, FÉE COUTURIÈRE (FAIRY DRESSMAKER). The Architecture of Memory: Works from a Private Collection. 1911 - 2010. Stamped with the artist's initials and numbered 3/6, painted bronze. $100.3 \times 57.2 \times 57.2 \mathrm{~cm} .391 / 2 \times 22 \frac{1}{2} 2 \times 22^{1 / 2}$ in. Conceived in 1963 and cast in 1993 , this work is number 3 from an edition of 6 , plus 1 artist's proof. 


\section{As emoções na arte e a arte das emoções}

A emoção é uma componente recorrente no discurso da nossa artista. Seja acerca da inexistência do amor na arte, seja acerca da cólera — tantas vezes 'teatralizada' na presença dos entrevistadores, seja acerca do medo ou do prazer, a emoção permite a revelação da artista e a artista permite a revelação do acto criador. A emoção, enquanto elemento integrante do discurso de Louise Bourgeois, dá o mote à dificuldade de entrevistar a nossa artista. A resposta pronta, o comentário irónico confunde(-se) na dispersão das considerações (mais ou menos freudianas) que remetem na maior parte dos casos para a vida pessoal da artista em detrimento da análise das suas obras, passadas ou presentes. ${ }^{4}$

As emoções trabalham em e para Louise Bourgeois a todos os níveis e portanto são parte integrante não só do processo criativo como de todas as actividades da vida humana. Os sentimentos são universais, os seus sentimentos são universais, como se comungasse uma compaixão pelos outros, como se quisesse experimentar uma estética da alteridade, baseada na autenticidade da emoção do estar-aqui-e-agora. A realização da escultura prende-se no fundo, com este movimento, com esta captação e retenção do instante. É a verdade com que se lança a essas emoções, que no ponto de vista de Mercedes Vicente, a realiza como escultora. ${ }^{5}$ Quer dizer, a actividade de moldar, de procurar a forma, de esculpir, é um desvelamento das linguagens e lógicas secretas que radicam na intimidade da matéria, tal como a criança que aperta a plasticina e a estica criando formas. A escultura para Bourgeois assume a importância do corpo, a sua espacialidade, a sua disposição; a escultura permite manejar e tornar visível certas realidades, quer dizer, confere legitimidade às possibilidades que proporciona como sejam a vivência do medo, da dor, etc., no fundo de re-viver as experiências do passado (emocionais-vivenciais) objectivando-o (Bourgeois, 2003, pp. 227-228); por isso refere que a

\footnotetext{
$4 \quad$ A este respeito refere-se também Mercedes Vicente: «en las conversaciones, solo una pequeña parte se reserva a detalles formales de la obra. Su discurso fuertemente psicológico freudiano gira en torno al monotema al que ha dedicado toda su vida, la emoción contenida en los traumas de la infancia y la relación con su familia. [e concluí a entrevistadora] Su figura violenta y agresiva y la verbalización de sus emociones es la defensa a su fragilidad». (Vicente, 1995, p. 27). 5 «Louise Bourgeois incide en que sus emociones son universales, la particularidad de los hechos no nos separa, pero la desgarradora fuerza con la que desnuda sus heridas es incomparable, y no la victimiza, sino que le concede una grandeza que la salva de la indulgencia. La autenticidad con que se lanza a sus emociones la realiza como escultora». (Vicente, 1995, pp. 27-28).
}

escultura é uma necessidade. ${ }^{6}$ Assim se compreende, por exemplo, que na entrevista com Paulo Herkenhoff, Bourgeois afirme que o corpo é uma escultura existencial. Para Louise Bourgeois a escultura é quase uma forma de libertação, uma forma de realidade superior como a artista lhe chama, uma forma de entendimento sobre a realidade tangível.

No artigo de Mercedes Vicente, encontramos o eco destas considerações nas suas próprias palavras: «a minha escultura permite-me reviver o medo». (Vicente, 1995, p. 28). Mas são os sentimentos, as emoções, como refere a entrevistadora, que fazem precisamente com que Louise Bourgeois encare o seu trabalho como uma tarefa necessária, permitindo-lhe ao mesmo tempo a purificação dessas emoções (uma ideia que já havíamos visto anteriormente).? Aliás outra coisa não quer significar a fé que Louise Bourgeois descreve; a fé no seu trabalho, a entrega no processo criativo é um acto de pura entrega do íntimo na intimidade. De facto, o artista quer encontrar o gozo ingénuo, a relação primitiva dos objectos e das sensações, se quisermos, quer redescobrir a realidade e a sensualidade dos cheiros enquanto cheiros, das cores enquanto cores, das texturas enquanto texturas, da realidade enquanto realidade. A arte é, ou melhor, a arte não deve ser um sistema finalístico porque isso será decretar-lhe o asfixiamento que os objectivos impõem, condicionando no percurso o próprio processo criativo. Arte de Louise Bourgeois está para a escultura/instalação como a música está para Bartók (a música anti-teleológica de Bartók é a tradução desta mesma ideia). No entanto, em Bourgeois as emoções estão à flor da pele. Criar é viver (de um certo modo) as emoções. Seja a dor ou o medo, a cólera ou a felicidade, as emoções fazem parte integrante da condição humana. É como se a angústia da condição humana fosse essencial ao processo criativo, como se fosse essencial à meditação (Júlia Kristeva que nos permitimos parafrasear referia: «só pode falar de melancolia aquele que escreve de dentro dela») ou como diria Kierkegaard, a boa angústia faz dançar.

6 «I do sculpture because I need, not because I have fun. I have no fun at all-in fact everything I do is a battlefield, a fight to the finish. It is not a battlefield; it is a battle and a fight to the finish. So if I have pleasure it is definitely sadistic and masochistic pleasure, not a casual one».

7 «Lo que realmente hace trabajar a Louise Bourgeois es la cólera. El arte significa una purga parea sus emociones. La agresión o destrucción es una forma de catarsis tan importante como lo es la realización de las imágenes para organizar estos sentimientos que la poseen». (Vicente, 1995, p. 33). 
Há em Bourgeois duas grandes emoções de que a artista fala quase sempre: o medo e a dor. A criação artística é um modo de metamorfose, de ultrapassagem dessas emoções como por exemplo, pode ser encontrada nas Cells. Estas instalações representam quase sempre uma forma de expor o medo (como veremos mais adiante), de expor outras realidades, sejam em sentido figurado ou não como o caso da dor.

\section{Erotismo e abstracção: dentro e fora, matéria e forma, tudo e nada}

Louise Bourgeois refere que «não podemos compreender a arte erótica se formos completamente inocentes» (Bourgeois, 2003, p. 75). Repare-se que também Henry Miller refere esta mesma ideia acerca do obsceno: «nada seria considerado obsceno (pelo menos essa é a minha intuição) se os homens fossem até ao fundo dos seus mais íntimos desejos». (Miller, 2004, p. 42).

A inocência, a existir, configuraria um lugar de exclusão do próprio sujeito, pois que seria impossível a vivência com a linguagem, com os símbolos, etc. Exige-se, pelas palavras de Bourgeois, uma experiência prévia para a contemplação da arte erótica. Mas essa experiência prévia de algum modo está já dada na intimidade, que vamos descobrindo à medida do conhecimento que adquirimos de nós próprios e do mundo. O erotismo nasce da relação entre as linguagens, os símbolos, os conceitos e as percepções das coisas no mundo, no fundo com a vida, ou como referia Henry Miller acerca do obsceno, «é todo o edifício da vida tal como hoje a conhecemos» (Miller, 2004, p. 48). Por isso e por si só, como refere Bourgeois, a arte seduz-nos. E porquê? Porque como se viu, a arte é relação estreita com a vida. É a dialéctica, a lógica interna destes acontecimentos, destes fenómenos que Louise Bourgeois retrata nas usas obras, plenas de vitalidade e urgência.

Nas instalações/esculturas como Lairs ou Fée Couturière (1963) ou Janus fleuri (1968) sentimos essa linguagem que quer conduzir à interioridade, à intimidade. $A$ procura pela interioridade que parece revelar a exterioridade e vice-versa. Mignon Nixon referiu precisamente que Bourgeois teria feito uso dos recursos do mundo exterior para gerar um outro mundo, que uma vez criado se manteria por si mesmo (Nixon, 2005, p. 180).

Para Daniel Robins, Lairs é como um «intricado mundo de relações entre o dentro e o fora» (Robins, 1964, p. 30).
A arte na sua vertente abstracta, e sobretudo numa escultura ou numa instalação (que possuem uma existência real) como as que Louise Bourgeois oferece, exige-se do espectador um esforço de antecipação, isto é, exige-se kantianamente as "antecipações da percepção". ${ }^{8}$ Trata-se de procurar aceder pela abstracção à forma da coisa percebida (sem necessidade de um apropriação duma significação ou de uma conceptualização), tentar aceder à forma que precede a visão objectiva, às intuições. Aceder à abstracção é aceder à vida, ou seja, trata-se de expor, pela escultura/instalação abstracta, para utilizarmos as palavras de Henri Maldiney, esse «momento de transcendência a partir do qual as coisas são coisas e nós as encontramos como reais», ${ }^{9}$ ou seja, captar o 'fenómeno-coisa' no seu dar-se enquanto tal, para lá do objecto imediato (a escultura). É este movimento, este ritmo que permite ver a forma em formação (para utilizarmos a formula emprestada de Paul Klee, gestaltung), que dá a ver a imagem em movimento de concretização, que proporciona e prepara a visão posterior objectiva. Mas a abstracção em Louise Bourgeois é uma relação sempre ligada à vida, sempre ligada a essa lógica secreta e íntima que procura a afirmação da existência.

Um mesmo movimento de abstracção que se dá quando Bourgeois emprega a violência destruidora, a violência do gesto, seja para a angariação, para a metamorfose da matéria, como faziam Artur Bual, Francis Bacon, De Kooning, Pollock, Basquiat, Franz Kline, Lucio Fontana, seja para a experimentação destruidora dos sentimentos e emoções, que no caso de Bourgeois, pode ser levada à letra (Bourgeois, 2003, p. 226). Há uma violência no gesto de Louise Bourgeois que a faz destruir, quebrar os materiais, para os voltar a observar, para os voltar a sentir, para os experimentar como uma nova emoção, para voltar a pensar neles, reunindo-os, como se os coleccionasse, fazendo lembrar Santo Agostinho acerca do pensamento. Reunir esses

8 Pode ler-se em Kant a propósito das antecipações
da percepção, e do papel da sensação na captação do real:
«Antecipações da percepção - O princípio destas é: Em todos os
fenómenos o real, que é o objecto de sensação, tem uma grande-
za intensiva, isto é um grau*» e esclarece o autor, «O princípio que
antecipa todas as percepções como tais exprime-se assim: Em todos
os fenómenos, a sensação e o real que Ihe corresponde no objecto
(realitas phaenomenon) têm uma grandeza intensiva, isto é, um grau».
(Kant, 1994, p. 201).
$9 \quad$ Refere Maldiney: «abstraire ne consiste pás à dépouiller les
choses de leur qualités secondes pour les exposer dans le simple
appareil de leurs qualités premières. Il s'agit de mettre à découvert ce
moment de transcendance par où elles sont choses et au niveau duquel
seulement nous les rencontrons réelles ». (Maldiney, 2000, p. 192).




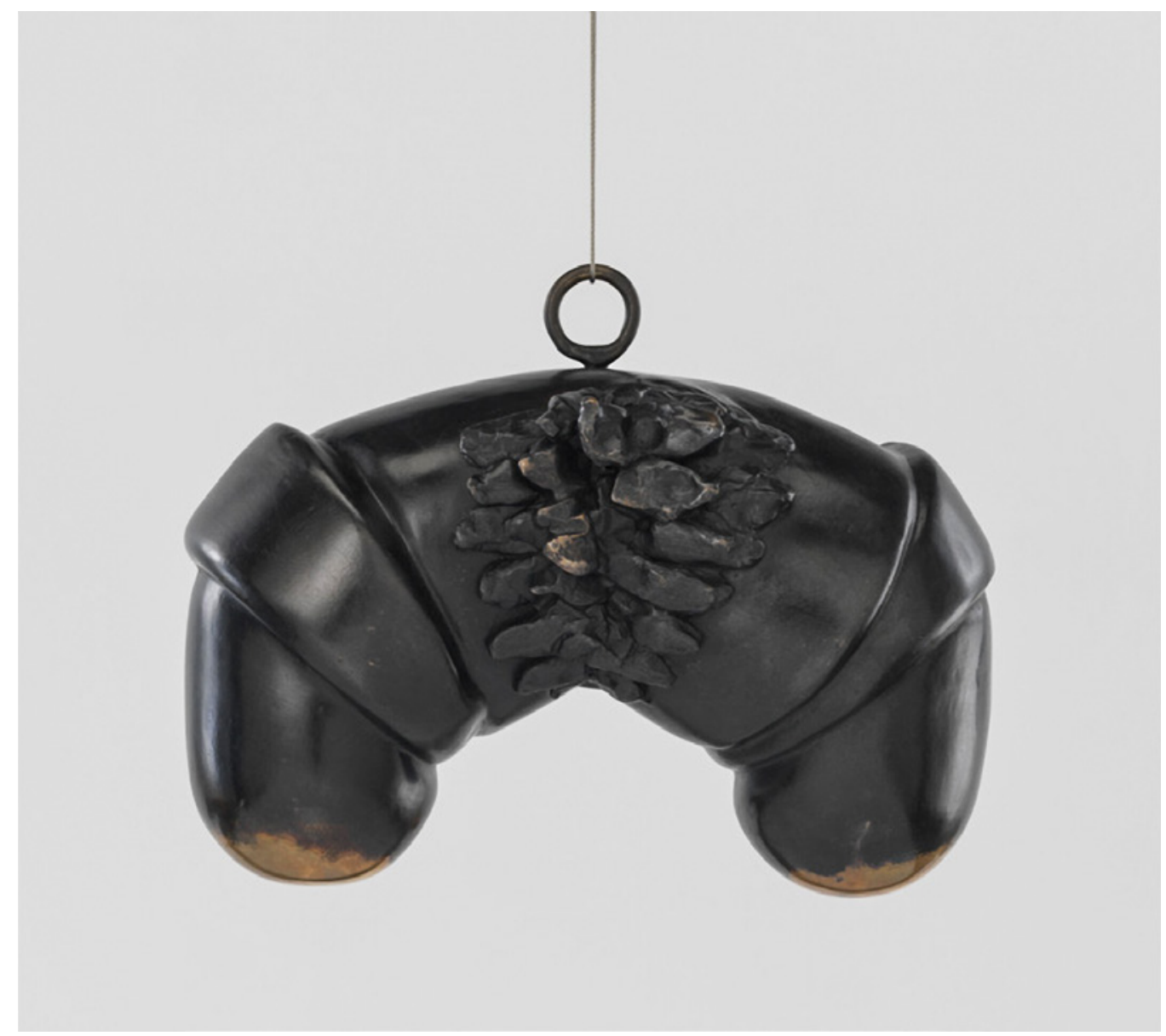

Imagen 3. Louise Bourgeois, Janus, 1968. Collection The Easton Foundation. (ㄷ The Easton Foundation/ Licensed by VAGA, New York. Photo: Christopher Burke. FROM: https://www.diaart.org/collection/collection/ bourgeois-louise-janus-1968-I-2003-135

materiais quebrados, juntar a observação das emoções, é um esforço no sentido de constituir um mundo, é um esforço no sentido da ordenação do caos. Na entrevista com Christiane Mennicke, Bourgeois diz mesmo que o seu trabalho não é explícito, de que ela própria não é descritiva. De facto, é a realização da forma, enquanto linguagem própria, que permite a sustentabilidade do trabalho (Bourgeois, 2003, p. 75).

A abstracção tem que ver com a procura da forma, com a exaltação da forma, com a arte, com o combate que a arte trava no seu dar-se ao mundo. A abstracção que a artista procura é a abstracção que Ihe permite aceder a uma certa dialéctica que se verifica no combate entre a interiorização e a exteriorização da intimidade das coisas tomadas em si mesmas, quer dizer, no seu íntimo, ou como refere Lucy Lippard «na arte (assim como suspeitamos que sucede com a artista) a forma e o informe acham-se entrelaçados num combate constante».10

\section{Para uma metafísica da intimidade}

Nas exposições de Louise Bourgeois sente-se (a criação de) uma atmosfera de solidão e intimidade. Não uma qualquer solidão que remete para um isolamento, para uma individualização do sujeito, mas uma solidão feita de Eu's, feita de um Eu que remete para um Nós. É um espaço de intimidade, onde Bourgeois procura realizar esse desocultamento do estar só, onde procura desvelar a intimidade das coisas. A colocação das

10 «En el arte (así como sospechamos que sucede en la artista) la forma y lo informe se hallan entrelazados en un combate constante. El resultado es una muestra, pocas veces tan el descubierto como en este caso, de la relación de intimidad entre arte y su creador». (Lippard, 1990, p. 204). 
peças (quase sempre) em grandes espaços (por vezes, grandes espaços abertos), geralmente sem suportes de qualquer ordem, com uma iluminação nitidamente insuficiente, quase na penumbra, obriga a que o espectador faça esse jogo de aproximação, esse jogo de se deixar seduzir pelo encantamento da intimidade, como o que se dá em realidade no ser humano através da polaridade interior/exterior. Esta atmosfera exige «um comprometimento do espectador» como referiu Patrice Marandel, para que seja possível uma interpretação. ${ }^{11}$ Mas é também um apelo constante, não só à participação do espectador como à imaginação do espectador, dado que as tendências naturais coexistentes que presidem ao trabalho de Bourgeois a isso obrigam, entre racionalidade e sensualidade, como mencionou Valeria Schulte-Fischedick. ${ }^{12}$ Poder-se-ia dizer que a obra de Bourgeois desafia os limites do convencional, convocando a imaginação a uma subversão das diferenças sexuais, dos géneros artísticos e, portanto, a uma abolição ou suspensão dos limites conhecidos ou admitidos nas artes plásticas.

A intimidade, estamos em crer, seria para Bourgeois uma estrutura sem determinações. 0 íntimo surge como espaço neutro, como espaço que não põe em causa o mundo. É a partir da experiência da intimidade que a criação ganha sentido, porque é precisamente a partir da intimidade como fundo que se redescobre o sentido e valor das coisas que estão no mundo. Ganhar intimidade com algo (por exemplo da artista com as pedras, com a madeira, o papel) é aceder ao seu íntimo, é descobrir a essência das coisas. Entrar na intimidade é descobrir o seu valor intrínseco. Por isso não é, não pode ser contraditório que a compaixão se gere a partir da intimidade, isto é, no sofrer com as coisas, com a existência das coisas, dá-se o acesso ao seu íntimo. É de novo o existencialismo a ser chamado ao diálogo com Bourgeois. $O$ sofrer-com não significa apenas a paixão no seu sentido mais religioso (o compadecer com), mas o sofrer como ser afectado, como deixar-se afectar pela existência das coisas. Poderemos asssim dizer que a intimidade no íntimo é assim fonte criativa para a artista porque todas as coisas são percorridas pelo mesmo fundo.

\footnotetext{
11 Cf. Marandel, Patrice, «Louise Bourgeois» in Art International, Dec. 1971, pp. 45-46.

12 «Much more they allow themselves to be described as an individual formation between abstraction and figuration, amorphous and biomorphus. They present a midposition between minimal and postminimal art, and confirm once more the coexistence of these two tendencies, often described as the opposite poles of rational and sensuality». (Schulte-Fischedick, 2003, p. 110).
}

É essa emoção que se quer re-encontrar, que se deve encontrar na arte, tal como refere Louise Bourgeois acerca de Bacon: «a intensidade dos trabalhos de Francis Bacon toca-me profundamente. Eu reajo positivamente. Eu simpatizo. 0 seu sofrimento comunica. A definição de beleza é uma espécie de intimidade no visual. Eu sinto ainda assim por Bacon mesmo que as suas emoções não sejam minhas» (Bourgeois, 2003, p. 229). Arte e emoção, confiança e fé na criação, re-criação dos espaços e tempos da intimidade, que permitem não só a re-criação interior mas exterior desse mundo. Criar é viver duas vezes, como dissera Albert Camus, e permitimo-nos dizer, criar é fazer viver duas vezes. A criação artística, como vimos anteriormente, é um acto de fé, quer dizer, é um acto que exige entrega, devoção, obstinação e que significa acreditar nas emoções, nos gestos, nos actos. Assim se pode compreender a admiração por Francis Bacon, ou por Gaston Lachaise, ${ }^{13}$ mas não por Duchamp, que «não confia nas suas emoções». ${ }^{14}$

Intimidade é também erotismo na sua vertente expositiva, na sua mostração e ou exibição exterior Refere Mignon Nixon, «para Bourgeois, o erotismo é uma projecção do observador, projecção de que se serve, é preciso admiti-lo, ao parodiar essa carga sexual perante a qual se distancia». São formas eróticas que pronunciam caminhos já percorridos: parece haver uma constante sugestão a uma qualquer anatomia do sexo, a uma linguagem universal-particular, que leva a um erótico ambivalente que simboliza a actividade e a passividade, seios e falos, reunidos na unidade mística do círculo originário feminino-masculino, que leva a que Louise Bourgeois fale de um estado 'pré-sexual' onde se diluiriam fragilidades e preconceitos. É este o 'vocabulário' que a nossa artista fala e que faz falar pelas suas obras. ${ }^{15}$ Por exemplo, a representação fálica,

13 «Contrary to Don Juan, and to what many feminists may feel, Lachaise did not exploid women but enjoyed them. To be a sex object is a flattering experience. [...] The formal distortions in the late work, where the human body is deformed and enlarged, increased the audacity of Laichase's expression. These late pieces-Breasts with Female Organ Between (also known as Abstract Figure; large version), 1930-2, Dynamo Mother, 1933, In Extremis, c. 1934, Kneeling Woman, Hands on Head, c. 1930-5-reflect an extremely powerful and original vision of his relationship to this woman-as mother, as lover, as ideal, as god». (Bourgeois, 2003, pp. 213-214).

14 «Duchamp did not trust his emotions. He worked very hard at looking cool. I don't think that he felt cool. He wanted to put up a good front». (Bourgeois em conversa com George Melrod, publicada inicialmente na revista Atelier em 1994, p. 270).

15 Vejam-se as palavras de Mercedes Vicente, na análise do conjunto das obras de Louise Bourgeois: «las protuberancias que aparecen en esta época, la serie cumuls (cúmulos), constituirán una de las formas características del vocabulário formal de Louise 
diz Bourgeois, tem a ver, a um só tempo, com protecção e vulnerabilidade, "o falo é objecto do seu carinho" (Bourgeois, 2003, p, 223).

Através desta abordagem sentimos que as palavras da nossa artista ganham uma outra consistência e uma outra ordem de sentido: a «pornografia tem um valor terapêutico e devia ser permitida enquanto tal». ${ }^{16}$ Esbater as fronteiras da falsa inocência, quebrar os vínculos do obsceno através de uma metafísica da intimidade.

No Arch of Hysteria (1993) sentimos precisamente a afinidade que existe entre homem-mulher, a afinidade que existe no posicionamento do corpo enquanto objecto plástico, e esta tensão subliminar entre o corpo ser isto ou aquilo que suscita prazer. Tal como essa tensão existente entre o titulo da obra Fillete e a representação da obra, que obriga ao esforço de abstracção, ao esforço do percurso pelas intimidades. Nesta obra sentimos a tensão gerada na indefinição sexual. E sentimos também a intimidade do silêncio (Bourgeois diz mesmo que a «intimidade é silêncio») a percorrer o espaço.

A arte de Louise Bourgeois surge com o potencial de indexar a vida, a realidade a partir das íntimas abstracções que todos nós fazemos num ou noutro momento. Para utilizarmos as palavras de Filomena Molder, «a arte engendra-se numa tensão que suspende a vida e nos faz regressar a ela [e por isso] a arte abstracta de Louise Bourgeois tem a ver com gestos, estados de fazer e perceber que nos são familiares a todos: verter, derramar, furar, derreter, moldar, que procedem da nossa infância, de experiências precoces com o nosso corpo, enrugamentos de energia, cintilações» (Molder, 2005, p. 244).

O grande jogo da intimidade em Bourgeois passa de facto pela compreensão desses momentos em que 0

Bourgeois. Estas masas redondeadas que sugieren erupciones de paisajes entropomórficas y que recurdean trabajos prévios como One and others o Fôret- similares en las posteriores Eye toe ye (1970) o Number Seventy-two (1972) - comenzarán en yeso, explorándose en diversos materiales hasta llegar al mármol en Cumul I (1969). Estas piezas que sugieren paisajes de contornos corporales evolucionan a esculturas con referentes sexuales como sleep (1967) y en algunos casos de forma explícita como Fillete (1968). Las formas de "cumuls" se desarrollarán crecientemente en mármol y los otros trabajos con connotaciones sexuales más agresivas adquirirán capas de latex, sugiriendo una textura más parecida a la piel». (Vicente, 1995, pp.31-32).

16 Cf. Bourgeois, 2003, Notas do diário de 1980-87, de 12 de Agosto de 1987. dentro e o fora, a interioridade e a exterioridade se parecem cruzar numa ténue fronteira. A instabilidade desta fronteira, a proximidade com a intimidade faz despontar nas palavras de Robert Storr, um movimento que pode precipitar «uma explosão centrifuga ou um imanente colapso centrípeto». ${ }^{17}$ Uma tensão que conduz e que é geradora do desafio constante que a artista pretende criar no espectador: o desafio da descoberta dessa metafísica da intimidade que subjaz a todas as coisas. Uma tensão que vive também das múltiplas referências sexuais, cuja polivalência, ao contrário de gerar um confronto entre sexos, os une segundo as mesmas categorias, da matéria, da forma, da abstracção, da figuração, do implícito, do explícito, do visível, do invisível. A tensão é gerada precisamente pelo esbater das diferenças (como referimos anteriormente, por exemplo em Fillete). Neste sentido vão as palavras de Borja-Villel quando refere acerca das múltiplas referências sexuais: «Unconscious Landscape (1967), por exemplo, configura simultaneamente uma vagina e múltiplos pénis. As Femmes Couteaux representam mulheres, que estão conformadas por sua vez ao modo de genitais masculinos. Estas imagens contraditórias não se opõem, mas complementam-se. A visão do espectador fluí de umas para as outras» (Borja-Villel, 1990, p. 198).

Spider é como que uma representação da bipolaridade entre o exterior e o interior. Não é só o imediato que é sugerido, como as teias que se tecem - um tema caro a Bourgeois até pelas tapeçarias que preencheram o seu passado (a sua infância) -, mas esse jogo que a instalação sugere ao ocupar um espaço, ao ocupar exteriormente um espaço que curiosamente obriga o espectador a percorrer a sua interioridade. ${ }^{18}$ Por isso a geometria, adquire extrema importância (Bourgeois, 2003, p. 55).

17 «Everywhere in Bourgeois's work, forms lean against or respond to the pull of their neighbours-proximity is simultaneously the promise and the threat of intimacy, and intimacy, by its very nature, is unstable. At any given moment the shifting equation of attraction and repulsion-the matching of opposites or the mutual antagonism of similar enteties-seems about to precipitate either an irresistible centrifugal explosion or an immanent centripetal collapse». (Storr, 1992, p. E3).

18 Mike Bai sugere uma abordagem semelhante: «by means of the fragments quality, which allows inside and outside the built space to become porous, Spider achieves something similar to what Francis Bacon accomplishes in some of his paintings: "the difference between inside and outside is challenged here, and that challenge is posed when body and space form one continuous field of dispersed elements".» (Bai, 2003, p. 141). Mike bai está a citar a obra de Alphen Ernst Van, Francis Bacon and the loss of self, London, Reaktion Books, Cambridge; Harvard University Press, 1992, p. 146. 


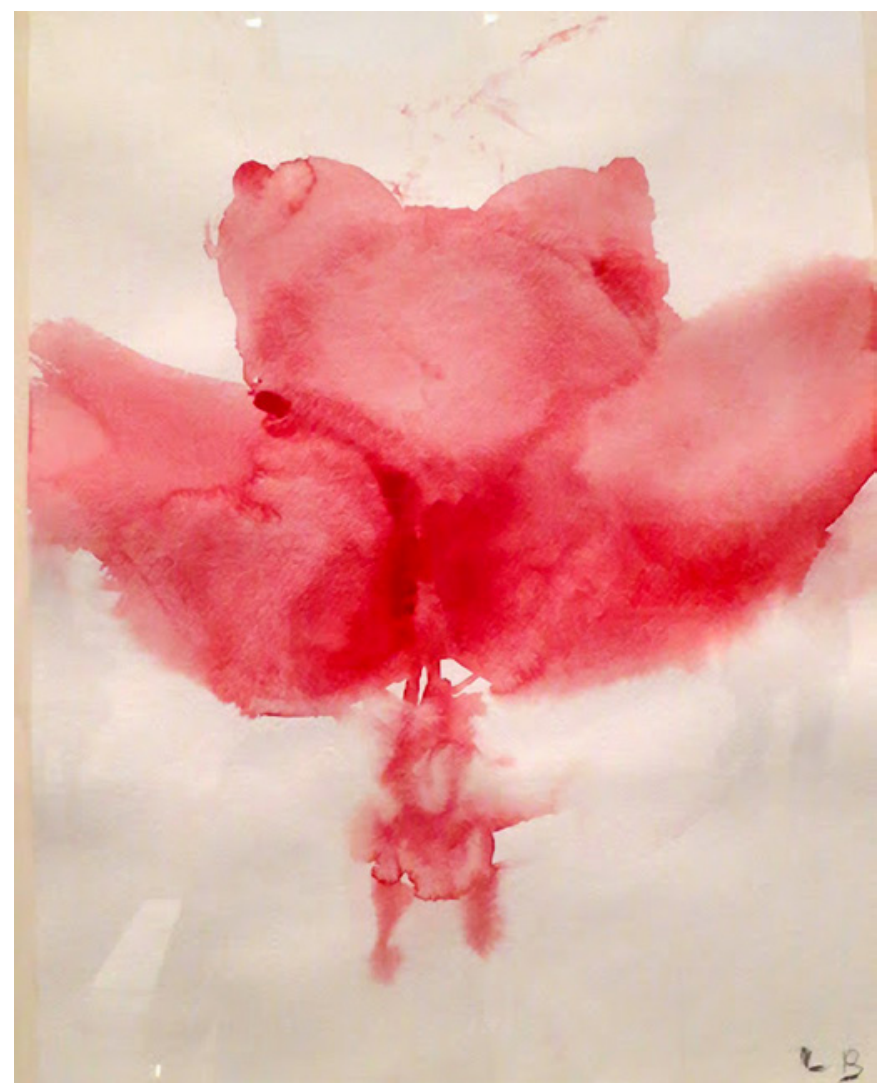

A espiral é uma dessas formas mágicas que parece concentrar todo o potencial de movimento e que parece potenciar ao movimento de qualquer obra, na sua força positiva, é uma forma que tenta controlar o caos (Bourgeois, 2003, p. 223). A espiral é uma figuração-abstracção que des-oculta a polivalência de uma qualquer obra. A força que imprime permite ao mesmo tempo esconder, ocultar, ou pura e simplesmente sugerir a abertura, como se se desfizesse a espiral, abrindo à revelação das formas e figuras. A espiral assume o papel de personificação de movimento dialéctico que é a vida, da transmutação da matéria em coisa viva, como acontece também por exemplo em Hundertwasser. Há assim um cancelamento como sugere Borja-Villel, da polaridade entre matéria e forma, ou figuração e abstracção. ${ }^{19}$ É a constante metamorfose das figuras e das matérias, as permutações de géneros sexuais, as aparentes reversões quer da lógica do olhar, quer da linguagem, como por exemplo as que se verificam em Harmless Woman (1969) ou Fragile Goddess e Heart

19 Refere-se assim Borja-Villel sobre esta temática: «Existe una continuidad entre ellas, que es bien patente en sus dibujos, en los que una forma en espiral puede desarrollarse en un ojo, un pecho o un pene, para acabar de nuevo en una espiral, cancelándose de este modo la polaridad materia-forma, figuración-abstracción». (BorjaVillel, 1990, p. 198).
Imagen 4. Louise Bourgeois, The Birth (2007). https://tinyurl.com/ysxrd4jr

(1970), embora Robert Storr prefira indicar outras, ${ }^{20}$ que reenviam a uma dialéctica íntimo-extímo que configura um lugar de absoluta perscrutação da intimidade sobre a espécie humana. Na série de pequenos desenhos intitulada Self-Portrait (2007) sente-se precisamente este trabalho em torno da metamorfose (quando a

\section{Esta concepção está bem patente no discurso de Robert} Storr, e que nao podemos deixar de citar: «... under constant metamorphosis, Bourgeois shapes catalogue the seemingly inexhaustible permutations of sexual contrariety and consaguinity. In its male incarnation, for example, Sleep is the antithesis of the hardshafted Fillete or the thick lingam-like shapes bunched together in Colonata Clamart and kindred pieces. Collapsing upon itself, like a soft, recoiling version of the outward spiralling Labyrinthine Tower, it resembles nothing so much as a spent penis, and hence represents masculinity at its most fragile and least threatening state. If the menace of castration haunts Fillete, then in Sleep a less drastic 'deflation' of virility takes place. That is only part of the point, however. The Freudian concept of penis envy assumes that female sexuality is predicated upon the lack of the phallus whose vestigial biological form is the clitoris. In Sleep and its variants, Bourgeois has reversed the logic of that argument by looking for the womanly characteristics of men, suggesting, in effect, that the retracted male organ imitates the female genitals and breasts. Transposing the psychological latency of early adolescence into palpable, flesh materiality, Bourgeois imagines a undifferentiated genitalia of mammoth proportions, a kind of hermaphroditic 'shunga' sculpture whose enormous attributes proclaim the obsessive eroticism of the pre-pubescent changeling». (Storr, 1992, p. E4). 
mulher se transforma em flor e dos seus peitos se produzem cinco pétalas, provavelmente remetendo para os membros da sua família, como sugere Duncan). Um outro exemplo deste jogo metafórico e metamórfico, que é ao mesmo tempo erótico e utópico, ao mesmo tempo sensível e provocador, pode ser encontrado num dos últimos trabalhos da artista, a saber, The Maternal Man (2008), um grande guache em tons de vermelho onde se adivinha um homem grávido. Cor adoptada por referência ao sangue e à vida. ${ }^{21}$ É de novo o tema "emoções" a vir ao de cima (mas com novos contornos), tal como havíamos encontrado por exemplo nas Cells, que falavam de receios e de prazeres, como local onde tudo parece e poderia ocorrer; "medo é dor" (Bourgeois, 2003, p. 205). Tal como a memória. A memória tem esse papel de trazer num processo de reminiscência os tempos vividos, as recordações e as histórias, e que como que permitindo a catarse das emoções (Bourgeois, 2003, p. 362). A memória é um grande documento vivo, ou que faz viver, e talvez seja a memória das intimidades que a artista traz de novo nestes últimos trabalhos de 2007 e 2008.

De facto, nunca o tema "vida" esteve tão presente como nesta última série de desenhos/guaches, apelando ao desempenho da memória que cada vida vai desenhando, a partir precisamente da intimidade da concepção. É não só a cor vermelha que povoa todos os desenhos, mas a forma despreocupada $e$ desprendida como os guaches foram trabalhados, como se de facto no momento da criação artística, Louise Bourgeois os tivesse povoado de sangue. Seja The Good Breast (2007), The Feeding (2007), Mother (2008), The Birth (2008), ou The Umbilical Cord (2008), ou mesmo na instalação The Arrival (2007) (em que um

\footnotetext{
21 Todos estes trabalhos são em tom de vermelho (que a artista adopta desde os anos 90) e que a artista justifica na sua escrita, como bem alerta Duncan MacMillan, no seu artigo «Blood Ties» in Modern Painters - The International Contemporary Art Magazine, Maio de 2008, pp. 72-79, esta p. 75: «All these drawings are red, a color that, for Bourgeois, is loaded with meaning. As she has writen: Red is the colour of blood/ Red is the colour of paint/ Red is the colour of violence/ Red is the colour of danger/ Red is the colour of shame/ Red is the colour of jealousy/ Red is the colour of grudges/ Red is the colour of blame. [...] Whether flowers or humans are the subject, if $\mathrm{t}$ can portray such a union so affectionately, this blood is not spilled in anger. And here, Bourgeois opens a fresh perspective on one pf our deepest fears: why are we so afraid of blood? We are bloody, and to remind us, the artist has created a series of these blood-red drawings on the theme of both childbirth and pregnancy and calleds variously The Birth and Pregnant Woman. Indeed, blood here is always an image of life, not of death. [Duncan cita de Novo Bourgeois] The artist herself has said, "menstruation... it is your best, most creative time. It's a blessing"».
}

dorso de mulher apresenta duas cabeças, uma de cada lado $)^{22}$ sentimos o eco de um paradigma de transmutação que exalta a intimidade da e na espécie humana: a emoção de se tornar (a) ser.

\section{Concluindo}

A obra de Louise Bourgeois requer tempo, contemplação, reflexão. Requer o mesmo espaço que se dá às emoções - lugar do encontro íntimo de si a si. A arte tem a ver com a vida e com o lugar onde tudo se desenrola - o mundo. Mundo tecido na tessitura do real, da realidade feita de inter-subjectividades, encontro de vontades e criações, de manifestações criativas que brotam da intimidade da mente. A arte e a concepção filosófica da vida de Louise Bourgeois revela-se como expressão de uma essência tantas vezes ocultada - a intimidade. A exposição da intimidade é a revelação da interioridade metafísica que preenche o ser humano. Assim, a felicidade, quer seja da artista, quer seja da mulher que Louise Bourgeois é, passa pela sincronia, passa pelo equilíbrio entre a aceitação daquilo que se é e da aceitação daquilo que os outros são, na demonstração das suas diferentes intimidades.

Louise Bourgeois é assim a personificação de uma vivência da intimidade, de uma criação na e da intimidade, para usufruto de todos os amantes de arte. A metafísica da intimidade é a metafísica da humanidade.

\section{Referencias}

Alphen, Ernst Van (1992). Francis Bacon and the loss of self. Cambridge; Harvard University Press.

Bai, Mike (2003) «Anthropometamorphosis - Forking Paths and Crystals in Louise Bourgeois' Philosophy of

22 MacMillan captou bem este sentido da metamorfose nestas obras de Louise Bourgeois e não se pode deixar de citar: «In The Arrival, a limbless female torso stitched out of white cloth, with yellow colored fabric for the breast, and the nipples and lips picked out in pink, becomes a radical variation on the classic iconography of mother and child. The limbless woman has a head at both ends: one between the shoulders and the other identical, but smaller, projecting from her womb. The figure, reduced to pure reproductive functionality by the absence of limbs, represents the moment of birth, of arrival; but also, because of the apparent identity of the two heads, it suggests how at the moment, by a kind of metamorphosis, one person becomes two. [...] In The Feeding, a series of 10 drawings, Bourgeois shows a child at a breast, its mouth as wide and demanding as that of a baby bird». (MacMillan, 2008, p. 74). 
Temporality» in Mennicke, Christiane, «You have to be pigheaded» in Louise Bourgeois. Intime Abstraktionen [Intimate Abstractions], B. E. Stammer, K. Becker, A. Weitzel e Valeria Schulte-Fischedick,Eds) Akademie Der Künste: Berlim.

Bourgeois, Louise (2003), «Select Diary Notes 1980 1987» in Destruction of the Father. Reconstruction of the Father - Writings and interviews 1923-1997, London: Violette Editions.

Borja-Villel, Manuel J.,(1990). «Louise Bourgeois: la escultura como transgresión» in Louise Bourgeois, Barcelona: Fundació Antonio Tapiés.

Dubufett, Jean (1971). Asphyxiante Culture, Cultura Asfixiante, Lisboa: Publicações Don Quixote.

Herkenhoff, Paulo (2003), Louise Bourgeois, edited by Thyrza Nichols Goodeve. London: ed. Phaidon.

Kant, Immanuel (1994). Crítica dalRazão Pura. Tradução de Manuela Pinto dos Santos, 3a edição, Lisboa: ed. Fundação Calouste Gulbenkian.

Lippard, Lucy (1990), «Louise Bourgeois: de dentro a fuera» in Louise Bourgeois, Barcelona :Fundació Antonio Tapiés.

MacMillan, Duncan «Blood Ties» in Modern Painters The International Contemporary Art Magazine, Maio de 2008.

Maldiney, Henri (2000). Ouvrir le rien. L'art nu, La Versanne : Éditions Encre Marine.

Marandel, Patrice, «Louise Bourgeois» in Art International, Dec. 1971, pp. 45-46.

Mennicke, Christiane (2003), «You have to be pigheaded» in Louise Bourgeois. Intime Abstraktionen [Intimate Abstractions] Editado por B.E.Stammer, K. Becker, A. Weitzel e Valeria Schulte-Fischedick,em colaboração com a Akademie Der Künste: Berlim.

Miller, Henry (2004). Obscenidade e Reflexão. Lisboa: Nova Vega.

Molder, Filomena, «O que é que Louise Bourgeois sabe, que eu não sei?» in Estéticas e Artes. Controvérsias para o século XXI. Lisboa: Edição do Centro de Filosofia, (2005), pp. 225-248.
Nixon, Mignon (2005). Fantastic reality - Louise Bourgeois and a story of modern art, London: The MIT press-October books.

Pirandello, Luigi (1993). Sei personaggi in cerca d'autore - Enrique IV, Milão: Mandadori.

Robins, Daniel, «Sculpture by Louise Bourgeois», Art International, 8 (Out.1964): 2-5.

Rubin, William, «Some reflections prompted by the recent work of Louise Bourgeois» in Revista Arte International, Vol. 8 (Abril de 1960), pp.17-20

Schulte-Fischedick, Valeria, «Sensual Counterculture and Anti Forms - Louise Bourgeois in the context of the 1960's», In Mennicke, Christiane (2003), «You have to be pigheaded» in Louise Bourgeois. Intime Abstraktionen [Intimate Abstractions] Editado por B.E.Stammer, K. Becker, A. Weitzel e Valeria SchulteFischedick,em colaboração com a Akademie Der Künste: Berlim.

Simmel, Georg (2001). Filosofia do Amor. São Paulo, Livraria Martins Fontes Editora.

Sorel, Georges, «Le valeur social de l'art», in Revue de Métaphysique et de Morale, vol. 9-3 (1901): 251-278.

Storr, Robert, «Intimate Geographies - The Work and Life of Louise Bourgeois» in Art Press, no 175 (Dec. 1992): E3-E7.

Vicente, Mercedes, «El cuerpo de las emociones» in Lapiz - Revista Internacional de Arte, Ano XIV, no 117, (Dec 1995): 26-37. 